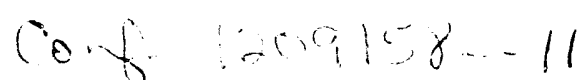

Preprint Volume 10th Symposium on

Turbulence \& Diffusion, AMS, 29 Sep -

2 Oct 92 . Portland, OR.

\title{
A THEORY FOR MIXED-LAYER-TOP LEVELNESS OVER IRREGULAR TOPOGRAPHY
}

\author{
Roland B. Stull \\ DE93 004036 \\ Boundary Layer Research Team, Dept. of Atmospheric \& Oceanic Sci. \\ University of Wisconsin, Madison, WI 53706 USA$$
\text { FGO2-92ER } 61361
$$

CONF-9209158--11

\section{OBSERVATIONS}

Observations show that the top of the mixed layer (ML) does not always follow the topography. Fiedler (1990) found the top of the afternoon mixed layer to be relatively level across the Rhine valley of Germany (Fig 1c). Earlier in the morning, however, the mixed-layer top (MLT) apparently followed the topography (Fig 1b). Lenschow et al (1979) observed a morning situation as sketched in Fig 1a, that was later modified by advection into a structure more like those sketched in Figs $1 \mathrm{~b} \& \mathrm{c}$.

As the altitude of the MLT changes relative to the topography, so does the local thickness of the ML. The local thickness affects pollutant dispersion, and controls the scaling of most turbulence variables within the ML. Levelness of the MLT might also affect appropriate flight plans for research aircraft.

\section{LEVELNESS DEFINITION}

Define a dimensionless "levelness number" by:

$L=\Delta z_{i} / \Delta z_{T}$

where $\Delta z_{i}$ is the altitude difference (relative to sea level) of the MLT, and $\Delta z_{T}$ is the altitude difference of the topography. The local altitude of the top of the mixed layer $\left(z_{i}\right)$ varies with horizontal distance, $x$, while $h$ represents the local thickness of the ML above the local topography.

Factors that affect the levelness are listed in Table 1 , where $t$ is time, $t_{*}$ is the convective time scale $=h / w_{*}, w_{*}$ is the Deardorff convective velocity scale, $C * D$ is the convective drag coefficient (Stull, 1992a), $U_{A}$ is the background mean horizontal wind speed,
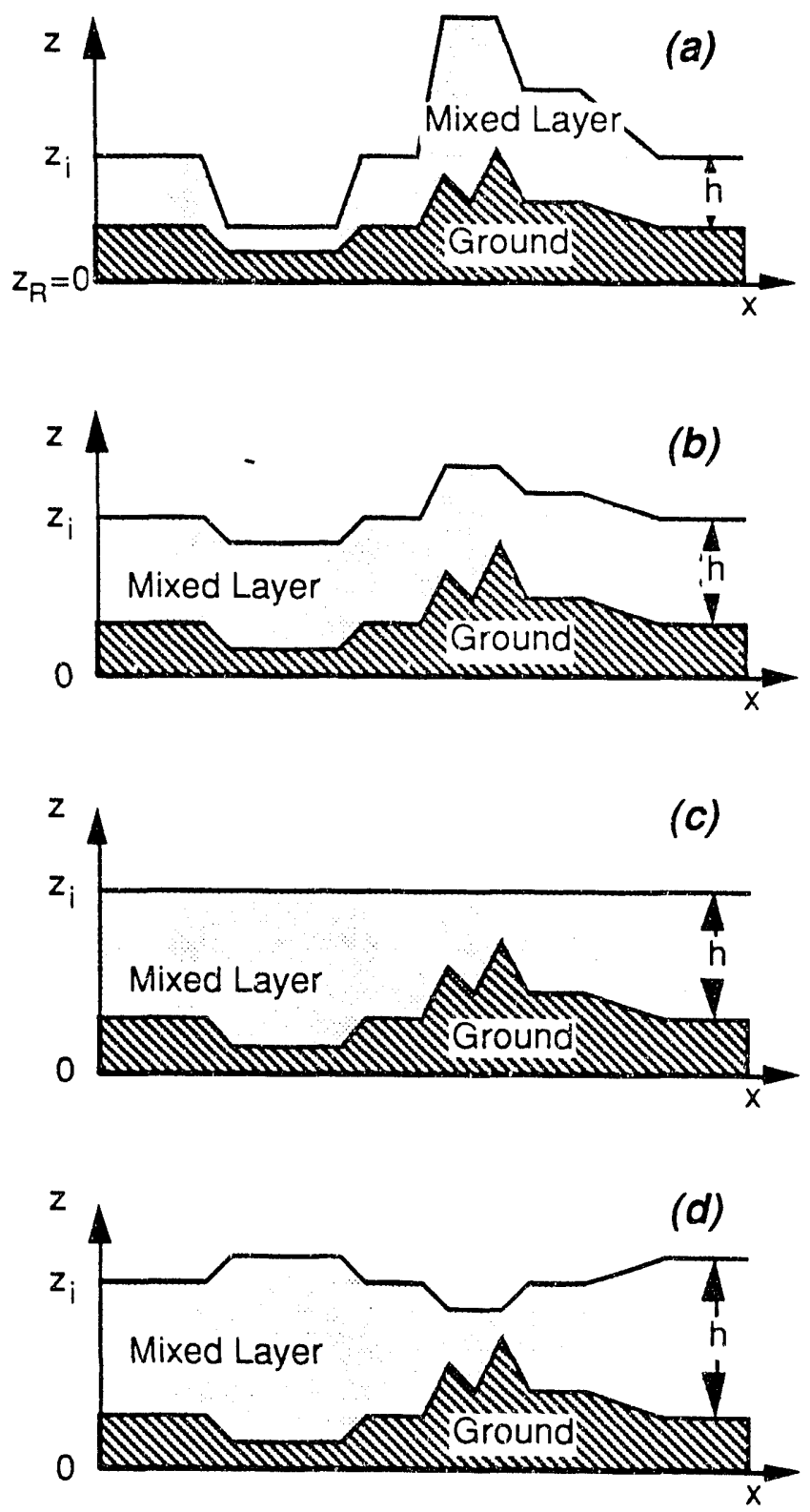

Fig 1. Four archetypical levelness situations:

(a) $L>1$, for a MLT that amplifies topo. variations

(b) $L=1$, for a MLT that follows the topography,

(c) $L=0$, for a level MLT, and

(d) $L<0$, for a MLT that varies opposite to topography. 
Table 1. Dimensionless variables affecting levelness

\section{Symbol Definition Name.}

$\begin{array}{ll}L & \Delta \mathrm{z}_{i} / \Delta \mathrm{z}_{T} \\ T & \mathrm{t} / \overline{t_{*}} \\ R & \Delta z_{T} / \bar{h} \\ C & \mathrm{C}_{*} D \\ \pi_{1} & \mid \mathrm{U}_{A} \mathrm{l} \cdot \overline{t_{*}} / \mathrm{s} \\ \pi_{2} & b_{s} \cdot \bar{t}_{*} \\ \pi_{3} & \overline{w_{e}} / \overline{w_{*}} \\ \pi_{4} & \bar{h} / \mathrm{s} \\ \pi_{5} & \Delta \mathrm{q} / \overline{\theta_{*}}\end{array}$

Typical Range

levelness

time

flatness

drag coef.

advection

divergence

entrainment

scale ratio

cap strength

-0.5 to 1.5
0 to 100
-1 to 1
0.023
0 to 200
0 to 0.05
0 to 0.2
1 to 100
1 to 500

Description

relative amount of terrain following

number of convective turnovers

relative depth of topography

mixed-layer drag

advective vs convective info propagation rate

synoptic and mesoscale relative spreading

ML growth rate relative to convective vigor

vertical ML depth to horizontal topo. dimen.

strength of capping stable layer

$s$ is the horizontal scale of the topographic feature, $b_{s}$ is the imposed synoptic and mesoscale divergence, $w_{e}$ is the entrainment rate at the top of the mixed layer, $\Delta q$ is the temperature difference across the ML top, and the overbar represents a horizontal average over the varied topography.

\section{TENDENCY}

When the mass conservation equation is applied to a ML over irregular topography, the levelness tendency is found to be a function of terrainfollowing terms, and leveling terms. Terrain following factors include entrainment at the top of the ML, advection, friction, and large-scale divergence. These oppose buoyant forces related to the cool mixed layer trapped under a warmer capping inversion, which tend to make the MLT more ievel.

Using the dimensionless groups from Table 1 , Stull (1992b) derives the following equation for levelness iendency:

$$
\frac{d L}{d T}=A \cdot(1-L)-\frac{B \cdot L}{C+(R \cdot B \cdot L)^{1 / 2}}
$$

where $A=\pi_{1}+\pi_{2}+\pi_{3}$, and $B=4 \cdot \pi_{4}^{2} \cdot \pi_{5}$.

Initial experiments with this equation indicate that the tendency is often a small difference between large forcing terms. This makes it very sensitive to errors. Numerical predictions made with this equation should either take very small time steps, or use a highly stable differencing scheme.

\section{EQUILIBRIUM SOLUTIONS}

By setting the time derivative in (2) to zero, one can solve for the equilibrium levelness as a function of the various forcings. Again, because of the sensitivity of the equation, care must be taken in its solution. We chose an iterative solution which is always stable and converges very rapidly, allowing easy computation and graphing in spreadsheet programs on desktop computers:

$L=\left[1+\frac{B / A}{C+(R \cdot B \cdot L)^{1 / 2}}\right]^{-1}$

The iterative equation (3) is a function of only four relevant variables: $L, A, B$, and $R$; plus the constant C.

As advection, divergence, and/or entrainment increase, these forcings tend to make the MLT follow the topography; that is,

$L \notin 1$ as $A \neq$. This is shown in Fig 2, for constant buoyancy $B=1$. However, as the height of the terrain feature decreases relative to the depth of the mixed layer, then the forcings are less effective at reducing levelness; that is, $L Æ 0$ as $R Æ 0$.

As the strength of the capping inversion increases, or as the mixed-layer depth increases, then the buoyant leveling force is able to drive the excess air off of high terrain fast enough to maintain a nearly level MLT; that is, $L \notin 0$ as $B \neq$. This is shown in Fig 3, for constant $A=1$. Both figures show that the MLT is level when the topography is flat; that is: $L=$ 0 when $R=0$. 


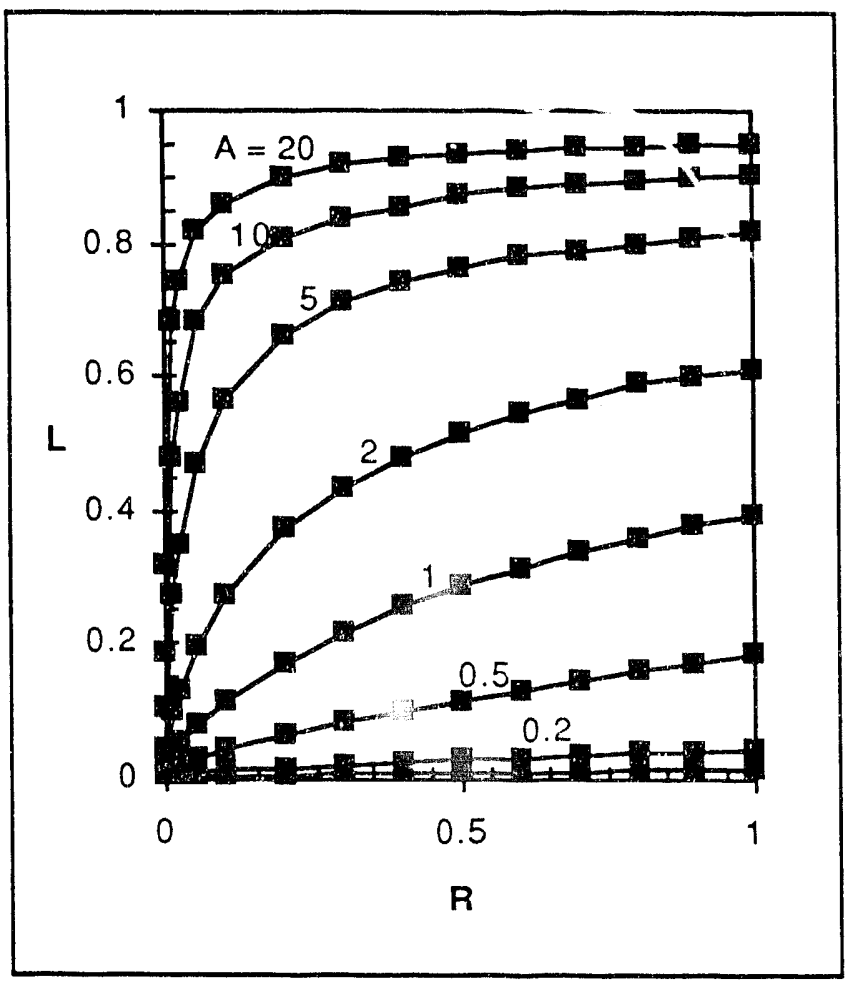

Fig 2. Variation of equilibrium levelness $L$ as a function of topographic flatness $R$ for a variety of forcing terms $A$ that tend to reduce levelness. The whole graph is for $B=$ 1 , corresponding to a fixed amount of buoyancy leveling force. $R=0$ is level topography, and $L=0$ is level mixed-layer top.

\section{CONCLUSION}

Deeper mixed layers tend to be leveler than shallow ones. Thus, mixed layer tops tend to become more level during the day, because the depth usually increases during the day. The mixed-layer top is less level over topographic features that have larger horizontal extent.

Acknowledgements. This research was supported by the U.S. Department of Energy under grant DEFG02-92ER61 361

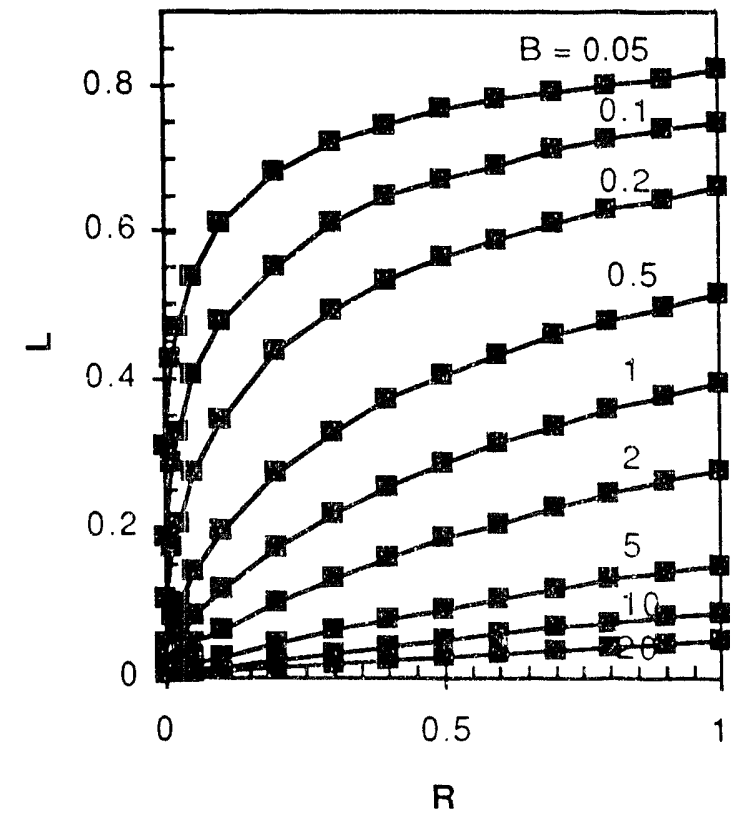

Fig 3. Variation of equilibrium levelness $L$ as a function of topographic flatness $R$ for a variety of intensities of buoyant forcing $B$ that tends to maintain levelness. The whole graph is for $A=1$, corresponding to a fixed amount of forcing tending to disturb the mixed-layer top away from being level.

\section{References}

Ficdler, F., 1990: (personal communication of data from the MESOKLIP field experiment).

Lenschow, D.H., B.B. Stankov, and L. Mahrt, 1979: The rapid morning boundary-layer transition. $J$. Atmos. Sci., 36, 2108-2124.

Stull, R.B., 1992a: A convective drag theory for surface fluxes. (Submitted to J. Atmos. Sci.)

Stull, R.B., 1992b: A theory for mixed-layer-top levelness over irregular topography. (Submitted to J. Atmos. Sci.)

\section{DISCLAIMER}

This report was prepared as an account of work sponsored by an agency of the United States Government. Neither the United States Grvernment nor any agency thereof, nor any of their employees, makes any warranty, express or implied, or assumes any legal liability or responsibility for the accuracy, completeness, or usefulness of any information, apparatus, product, or process disclosed, or represents that its use would not infringe privately owned rights. Reference herein to any specific commercial product, process, or service by trade name, trademark, manufacturer, or otherwise does not necessarily constitute or imply its endorsement, recommendation, or fayoring by the United States Government or any agency thereof. The views and opinions of authors expressed herein do not necessarily state or reflect those of the United States Government or any agency thereof. 


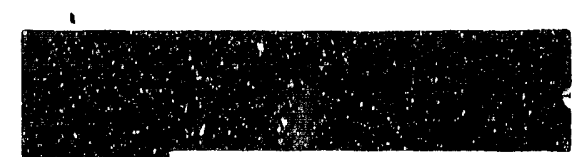

t)
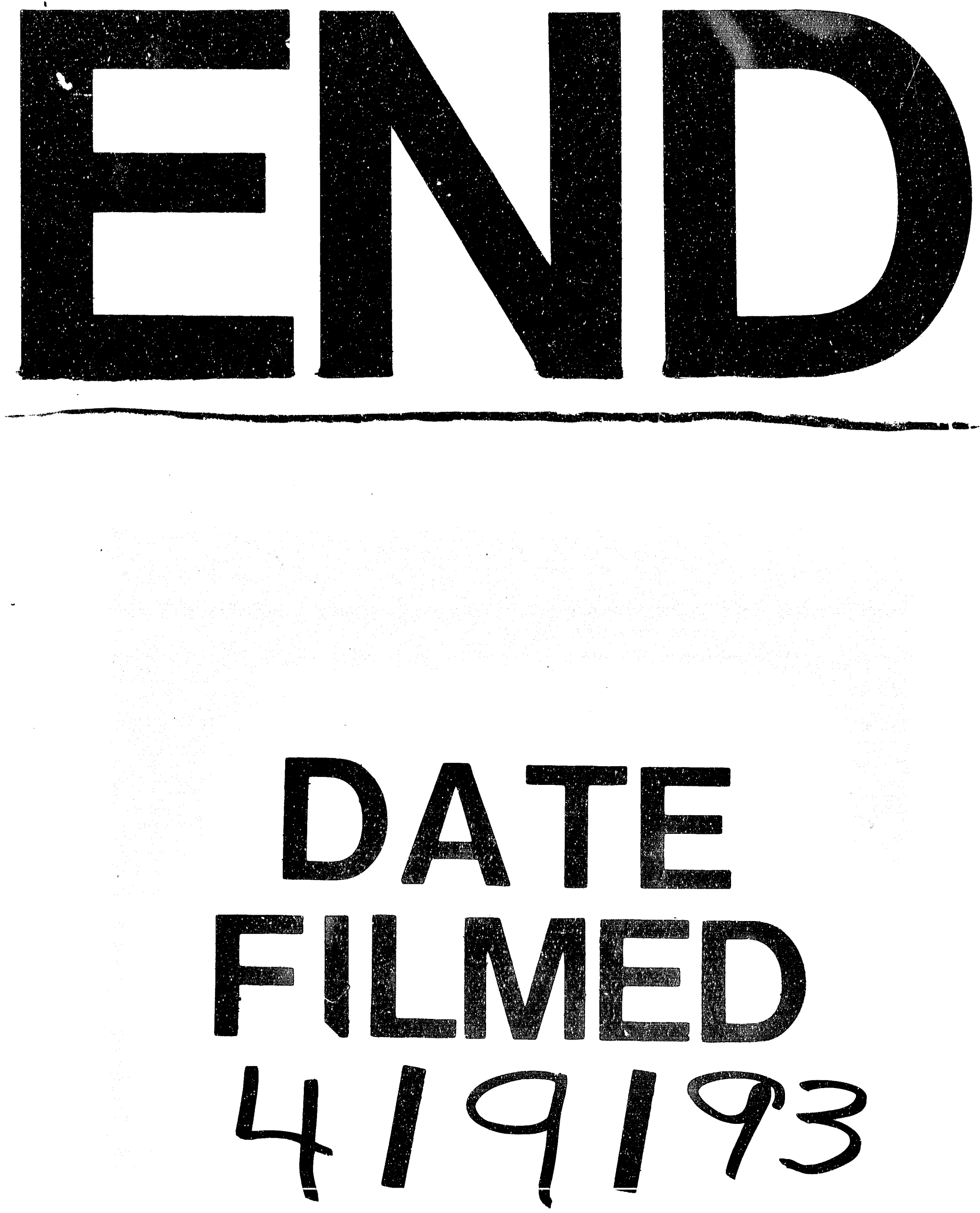
